\title{
Some Case Studies Concerning Information and Communication Technology Based Inclusion into University
}

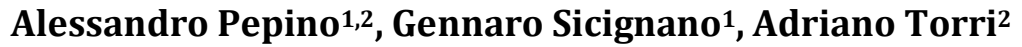 \\ ${ }^{1}$ SInAPSi Centre, University of Naples “Federico II", Naples, Italy \\ ${ }^{2}$ Department of Electrical Engineering and Information Technologies (DIETI), University of Naples "Federico II", \\ Naples, Italy \\ Email: pepino@unina.it
}

Received 16 December 2014; accepted 9 August 2015; published 12 August 2015

Copyright (C) 2015 by authors and Scientific Research Publishing Inc.

This work is licensed under the Creative Commons Attribution International License (CC BY).

http://creativecommons.org/licenses/by/4.0/

(c) (i) Open Access

\begin{abstract}
In recent years, a revolution occurs, in both the school and the university, in which many of the traditional education paradigms have been questioned. This phenomenon has been triggered on the one hand by the students, both in the school and the university, who make use of new information and communication technology based learning paradigms, despite the conservative resistance of most of the teachers; on the other hand also because of the inclusion needs of people with disabilities and specific learning disabilities who until now have been excluded from education at various levels or that they have to face their studies with great difficulty. The present paper discusses some examples of applications in which not only we explain how the technology makes these guys able to participate but also what the design methods are by which you define the actions characterized by a multidisciplinary approach individualized.
\end{abstract}

\section{Keywords}

Rehabilitation, Assistive Device, Education, Inclusion, Assistive

\section{Introduction}

The inclusion of students with special needs in an educational setting, even at university level is a complex process that can be described as multi-dimensional and multi-factorial process in so far as the variables involved are numerous and not always (in fact rarely) suitable for a deterministic treatment.

A couple of examples may help to illustrate such complexity and the challenges for anyone who is committed 
to promoting policies and practices of inclusion in education.

\section{Background}

In Italy, as in most western countries, there are specific laws to protect people with physical or mental disabilities (and, since 2010, with specific learning disabilities); at the same time-particularly concerning to the university context - there are no regulations for those young people with certain difficulties which are not related to these two areas, but which however have an impact on the learning process.

This may lead to some paradoxical situations: sometimes it can be the case that people with severe motor disabilities, but without any major consequences in the performance in terms of learning, and therefore does not require special measures or countervailing dispensatory, have the opportunity to receive much more support than students with issues related to an existential distress or incidents of discrimination, which, however, not having a clear identified "medical disability", are likely to find themselves often without any help, while they need complex psycho-pedagogical interventions (Valerio, Striano, \& Oliverio, 2013).

A second example concerns the use of technology: while it can be considered as accepted that it is often an essential success factor for the inclusion, by itself it does not ensure success, and does not reduce the complexity of the interventions; indeed, in some cases, it contributes to complicate the picture, due to the fact that sometimes the players involved do not have a clear awareness of these techno tools and then they inappropriately relate to them (making it necessary to mobilize different strategies-for example psycho-pedagogical - in order to make the technologies really effective and capable of deploying their potential inclusive).

We have cited only two cases - but the examples could be many more-in which the practice of the inclusion is complex, non-linear, multi-dimensional and, therefore requires the construction of systems that adapt to different skills and have at the same time a significant degree of integration (in order to prevent that any atomization and fragmentation of activities and services could bring to procedural difficulties to address cases that are always unique).

Since the law 17/1999 (Valerio, Striano, \& Oliverio, 2013) college students with disabilities are given the possibility to receive individualized support and equivalent learning pathways. This has in the years stated, for the first time, in the universities a principle of educational inclusion.

This historical innovation in some cases has had the effects of a real revolution. Thereafter, and in particular in 2010, the same principle has been adopted in respect of students with specific learning disabilities (dyslexia, dyscalculia, etc.) thus extending in the universities a practice in many cases already adopted, in schools (Valerio, Striano, \& Oliverio, 2013).

We can therefore say that these past 10 years have been, both for the school and for the University, a turning point for the ICT in education, even though the results of the system are still to come, certainly a number of points and traces for the future are uniquely specified.

In particular, no one can deny that the inclusion of students in the university and the school, can no longer disregard the use of ICT technologies, (Derer, 1996) and in particular the so called Web 2.0 technologies.

These technologies, however, more and more forcefully pervades our daily life; terms once reserved only to insiders as Information and Communication Technology (ICT), have now entered into common parlance, to show how their use has become pervasive and it represents, however, a valuable opportunity for anyone experience a difficulty or disability, temporary or permanent situation.

The new generations of students, in fact, have a way to communicate and to learn that it is completely different than in the past, and teachers are struggling to keep up the students.

In recent years it has also gone by stating a different culture of disability according to which term "disabled" is questioned and subject to different interpretations and applications, with several distinctions, in different countries.

It is certainly clear to all that disability is the result not only of the medical condition but also of environmental factors (The Kellogg College Centre, 2013) whereas many people refuse to be considered such as certain members of the deaf community, or people who believe they have learning disabilities rather than disability (Dommett, Devonshire, Plateau, Westwell, \& Greenfield, 2011).

For this reason in these last years, you prefer, in a general sense and in a logic of greater inclusion to talk about "special needs" in order to represent the difficulty of including these guys.

It is still very clear to the authors, that these distinctions and differences are always worthy of attention though 
to the point of not compromising the intervention effectiveness.

The operating staff, who is responsible for designing the solution for each student must investigate not only the cognitive and engineering needs, but also the social, environmental and individual ones.

In other words, the use of ICT in education for people with disabilities must be considered as part of a transsectorial approach in which many different involved skills must be considered.

In this sense, certainly one of the qualifying aspects of the work, that lies upstream of the present article, concerns the highly multidisciplinary approach ensured in order to draw up the plans for individualized inclusion for college students to define their own learning path through the appropriate technologies.

On this basis coding techniques based on the ICF (OMS, 2002), represent an important operational tool operating for the classification and definition of the various cases.

These criteria are the basis of the working model has been consolidated over the years within the Operations Staff of the Centre for Multidisciplinary University SINAPSI which, thanks to the appropriate use of information and communication technology has allowed many students with various difficulties to access to higher education, otherwise forbidden to them

Coherently with the indications of Riemer-Reiss \& Wacker (Riemer-Reiss \& Wacker, 2000), the solution is then drawn according to the specific needs and so shared with the recipient of the intervention.

The following pages will then report some case studies concerning use of ICT for educational purposes at the university, developed in the context of individual projects at the Centre for inclusion of students with disability of the University of Naples SInAPSi (www.sinapsi.unina.it).

We used fancy names to refer to the students, in the paper we have tried to focus not only on specific operational details but also on organizational aspects just as important item for successful management and sustainability of the realized projects.

\section{The Individualized, Multidisciplinary Design of Inclusion Projects}

At the University of Naples, In order to fulfill the obligations of the law 17/99, in supporting of students with disabilities, a special service university centre, called SInAPSi was created in which, within a specific multidisciplinary group a series of engineers, psychologists, educators work in, in order to develop, each individual student, as many inclusion projects, calibrated for the individual at $360^{\circ}$ in order to take into account all individual perspectives according to a working model established and matured over the years (Griffiths \& Price, 2011).

The operative workflow "Figure 1" requires that the student ask for "Reception Office" (Where two psychologists daily work) who is responsible for a preliminary analysis and for presenting the case to the "operational staff” consisting of psychologists, bio-engineers, and educators who then develop, by ICF bases approach, an individualized project which is agreed and signed by the student.

The operational staff is normally supervised for the strategic aspects by the multidisciplinary staff which actively participates in the management of the centre and consists of the operational staff, some external consultants and three professors, including the director of the centre; each of them is responsible for the SInAPSi areas (psychological, pedagogical and technological).

The individual project, depending on the case, is then coordinated by a case manager who is a member of one of the three SINAPSI operational areas, psychological, pedagogical and technological. The case manager is finally responsible for coordinating the work done on the field in general from the "Volunteers" belonging to the National Civil Service who works at the Centre.

As for the quality control of the workflow, multidisciplinary staff takes place on a fortnightly basis the audits and controls that ensure the smooth running and monitoring of each inclusion project. In summary, the key elements of inclusion projects for students are:

- Multidisciplinary approach guaranteed by the various professionalism who are working present into the staff.

- Individualized Design customized on the specific needs' and environmental factors for each student who makes requests.

- Use of a large number of volunteers or peer tutoring to ensure effective implementation and concrete outcomes to the inclusion project.

\section{Case Studies}

In the next pages will be presented some case studies. 


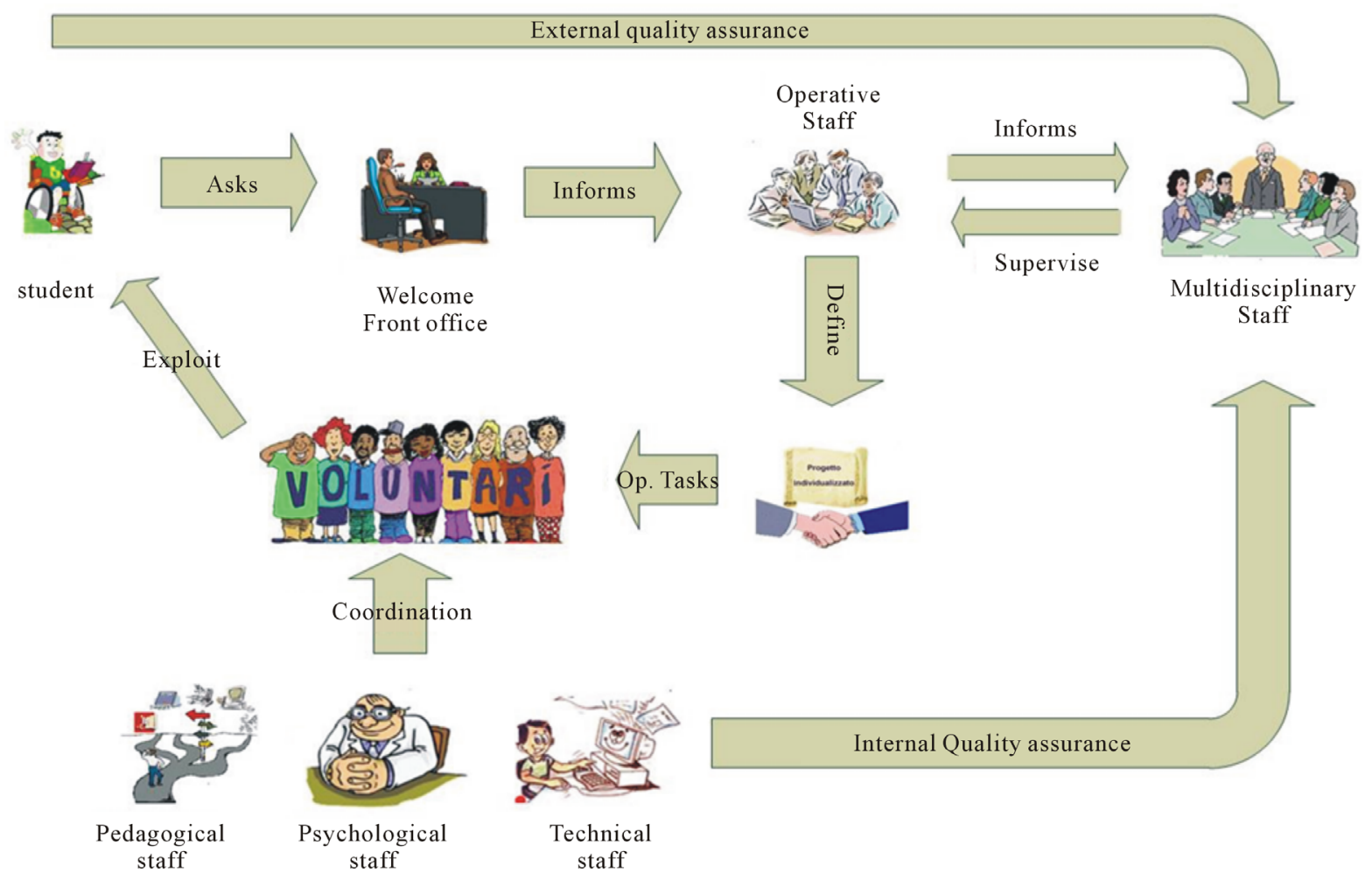

Figure 1. Operational Workflow for the management of personalized multidisciplinary projects at SInAPSI.

\subsection{Case Study 1}

Carlo is a student who, enrolled at the university, he became progressively blind. He follows a course of humanistic study, does not know the Braille and does not have computer skills.

Carlo is able to study exclusively by audiobooks, which in general could represent a further handicap because the limited availability of titles on the market and therefore it is limiting the achievement of a working autonomy for which it is fundamental the possession of computer skills.

The individual project developed by operational staff as first step consists of a preliminary information and awareness of teachers who, over a number of meetings, are made aware of the problem and, therefore, encouraged to work through the provision of educational materials; such material, normally is prepared by volunteers on the basis of manuscript, even handwritten, by the teachers.

The electronic text is then made available prior to the lesson to the student in a format accessible to him, in order to give him the opportunity to study it before class.

For the reasons already explained, the operational staff decided to provide to the student, a specific activity of fundamentals on computer science in order to enable him to replace the audio book to the PC and then to make him able to use several software aids, which are available for visually impaired, to study the electronic material made available by the teachers.

This approach also provides the student with a number of practical skills quite useful for future employment.

One of the most complex items in these cases is related to the difficulty of teaching at the same time both the use of the personal computer, and the screen reader. The screen reader

(http://screen-reader-software-review.toptenreviews.com) is a particular software device that allows a blind user, by using just the keyboard, to "surf" on the Windows desktop, listening through the voice synthesis, the textual content of the windows and at the same time "reading" through the braille display the same text.

Any images are read using by alternative text associated with them and which is normally always present in user interfaces that comply with the W3C accessibility requirements. The screen reader tool has now become a basic aid to blind students, the student will then hear and read with the fingers rather than with the eyes what the computer shows on the screen. 
Apart from the purely technical aspects, the transition from audiobook to computer it's still a very difficult step; audiobook is in fact a source of information which is typically one-way, while the screen reader requires that the reader pays a constant attention and active participation to the computer, and then a commitment and hard work that requires strong motivation by the student.

For these reasons, inclusion projects in general and this one in particular, are monitored and supported by psychologists who must assess and support also motivational elements.

As shown in "Figure 2", where is presented the stream of work, the awareness meetings with teachers were borne by the pedagogics of the group the technicians of Technology area have carried out special training sessions in presence on the theoretical and practical basics on computer system, introduction to network technologies and the internet technology; in these practical lessons, the teacher has paid special attention to providing the

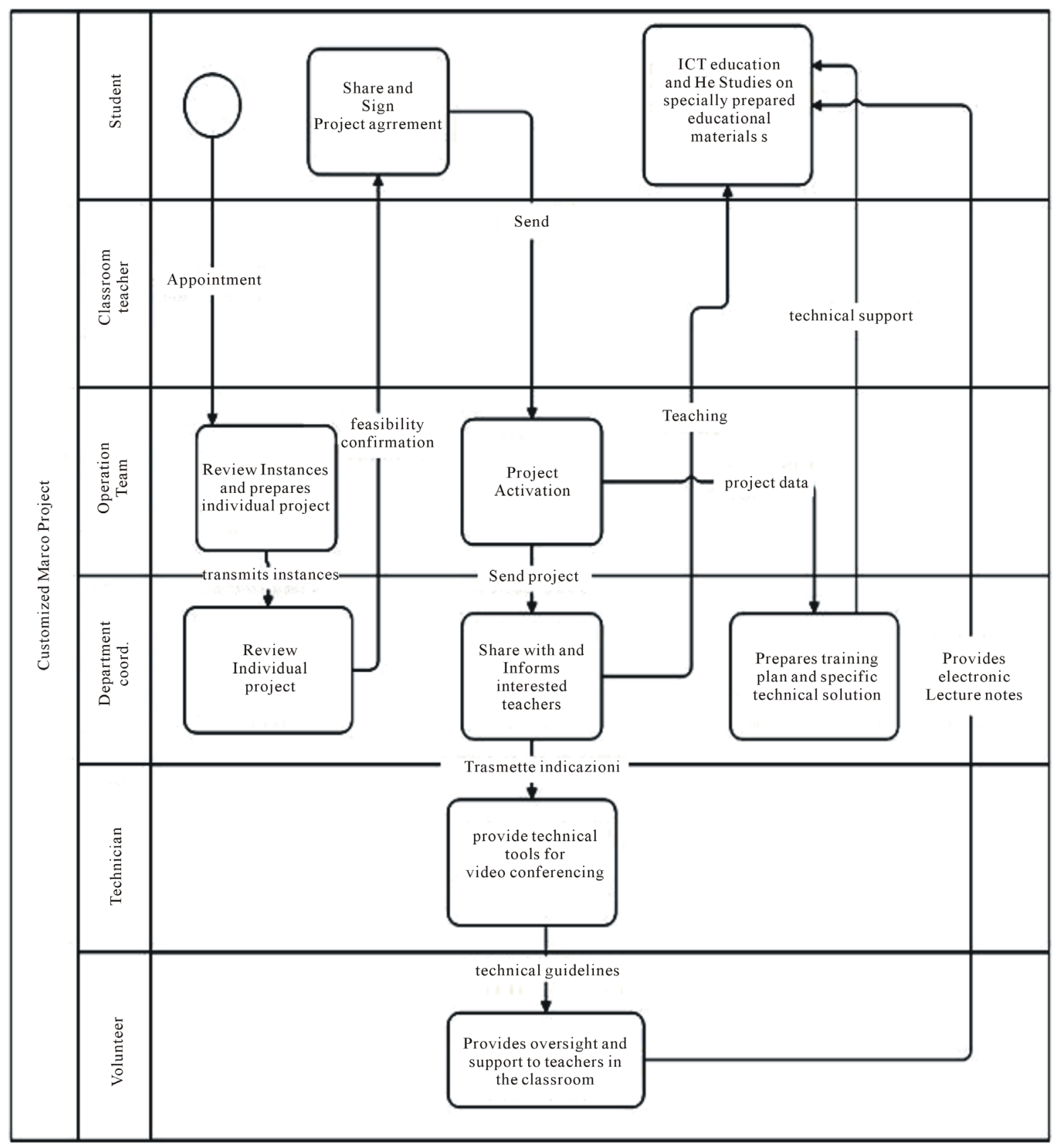

Figure 2. Operational workflow of the individual project of Case 1. 
basic concepts of graphical user interfaces of modern operating systems and the organization of various objects on the desktop screen in order to give the student enough confidence concerning the user interface.

For example, in order to explain how the icons were distributed over the desktop, we have used the desktop metaphor, as well as to provide the concepts of folders or nested folders the metaphor of Chinese has been used. During various training sessions, it also has been used tactile approach to facilitate the acquisition of concepts, putting objects on the desk and transferring, in this way, concepts of absolute and relative position of those objects.

The formative way put to use has dealt with following arguments, on the basis of a teorical/practical approach:

- Introduction on the structure of the computer, concepts on the operative system, application software, software screen reader;

- use of the operative system, management of the file system, use of menu;

- management and configuration of the screen reader;

- use of computer printing software;

- internet;

- email.

After some months of work the student has achieved an acceptable autonomy level in the use of computer in order to allow him to carry out daily activities such as: surfing file system, management of file, reading creation and modifications of text files, use of browser, and use of software for the management of email.

Carlo has also declared to be able to read more effectively texts of study provided to him in textual size instead that like audio file, in fact, by the computer today he can read and read back, in focused way, parts of the text of him interest beyond of the important possibility to found information and to communicate with teachers and colleagues by internet.

\section{Material Employ}

- Pc notebook, tablet, smartphone.

- Screen reader like JAWS (http://www.freedomscientific.com/Products/Blindness/JAWS) or NVDA (http://www.nvda.it).

- Communication software like Skype (www.skype.com).

- Remote support software like Team Viewer (www.teamviewer.com).

\subsection{Case Study 2}

Irene is a blind student that intend to face study of scientific subjects, in this case beyond the difficulties of the Case 1, it was added another hard particularly for blind people that concern mathematical formulas. All along blind people find hard problems because, despite of information instruments at their disposition, the structure of braille and generally of instruments that allow reading by blind people, typically serial, it is bad adapted to the read of formulas, being that typically two-dimensional (Ferreira, Helder, \& Diamantino, 2004) (Karshmer \& Bledsoe, 2002).

The operative stream trace also in this case that refer in "Figure 2", as opposed to the previous case, the student know the braille code, this is for sure an important element, inasmuch the knowledge of braille facilitate enormously the young blind people in studying and also in learning of use the computer (Reeta, 2012).

At the same way at the case 1 is then expected a specific phase of awareness of teacher for guarantee the availability of materials that even is anyway prepared and make it available in electronic format so as Irene can study it by screen reader and braille display that she already know in part.

However as the type of study that she want to start the operative staff has agree with Irene the necessity of increase her currently information competences, in order to support a gradual but progressive increase of the autonomy, in study and in relation with the teachers oriented especially to create the conditions to face subjects more advanced that it be presented in the resume choose from her.

Therefore, in the personalized project it was inserted a specific activity of information training oriented to allow to Irene to achieve a suitable level of autonomy in using the computer both with connection to applicative software of interest: screen reader, word processing, email, browser Internet e search engines, and in relation of software systems more specifics which for example BlindMath (Pepino, Freda, Ferraro, Pagliara, \& Zanfardino, 
2006) (Freda, Pepino, Pagliara, Ferraro, \& Zanfardino, 2008a) (Freda, Pepino, Pagliara, Ferraro, \& Zanfardino, 2008b) a scientific editor on purpose studied that allow in combination with the screen reader (in particular jaws) to read and edit the mathematical formulas.

Then, as regards problem of diagrams and graphics, through the support of Civil Service Volunteers, material supplied from teachers it has been converted in graphics "in relief "with the assistance of a particular device named "heat fuser”, “Figure 3”.

This technology use special sheets of paper covered just of microcapsules that have the property, in presence of heat source, of swell in case in cui that on their surface there is ink; this, then allow to realize easily some drawing with a relief effect. In fact is sufficient create the drawing on this type of paper, through the printer or by hand, then insert it few minutes in the fuser, to obtain a version "in relief" of the drawing marked.

Obviously the activity of awareness of various teachers of Irene provided from the personalized project, is also oriented to guarantee that the teachers will be aware of what is happening not only in order to the preparation of teaching materials but too for exams and for lessons, which Irene participated usually accompanied by a volunteer of Civil Service.

\section{Material Employ}

- Pc notebook with Windows 7 (http://windows.microsoft.com/it-it/windows/home);

- Screen reader (JAWS);

- Software BlindMath;

- Communication software (Skype, mail client Thunderbird);

- Remote support software (TeamViewer);

- Printer braille Juliet (http://www.brailler.com/);

- Heat fuser;

- Rubberized surface.

\subsection{Case Study 3}

Pasquale is a student enrol to a degree course that provide some courses with compulsory attendance unfortunately his health conditions prevent him to attend classes and therefore he wasn't in conditions to continue the type of study that he has chosen.

In this case the operative staff has to agree upon previously the personalized project with the representative of Department which course of study choose from Pasquale that he belong to.

The operative stream then is substantially different compared to previous cases, as in this case is not more a problem of sensitizes of the teacher but of teaching reorganization of whole course of study "Figure 4".

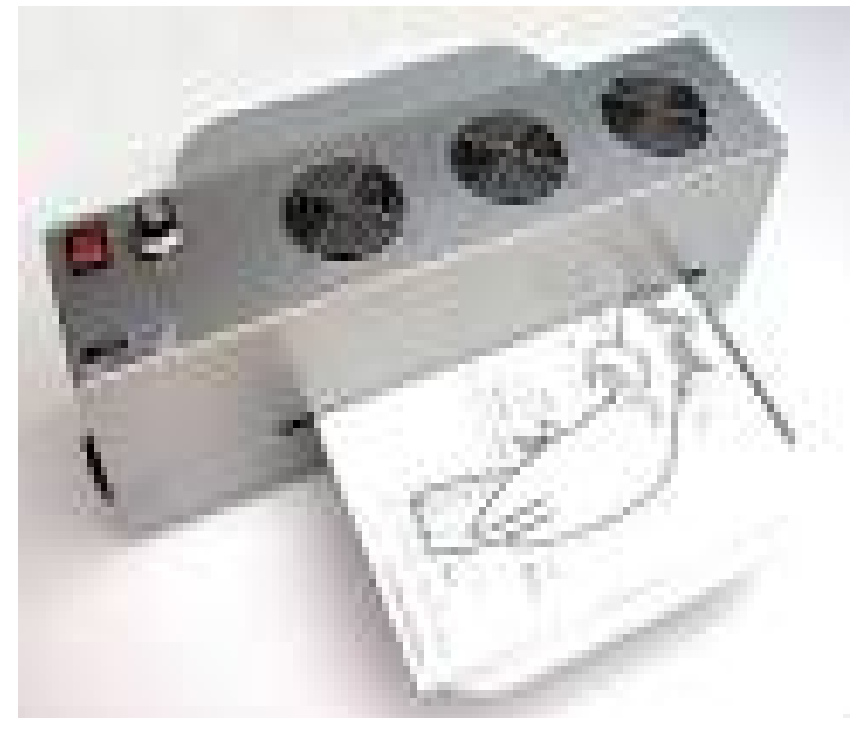

Figure 3. Heat fuser. 


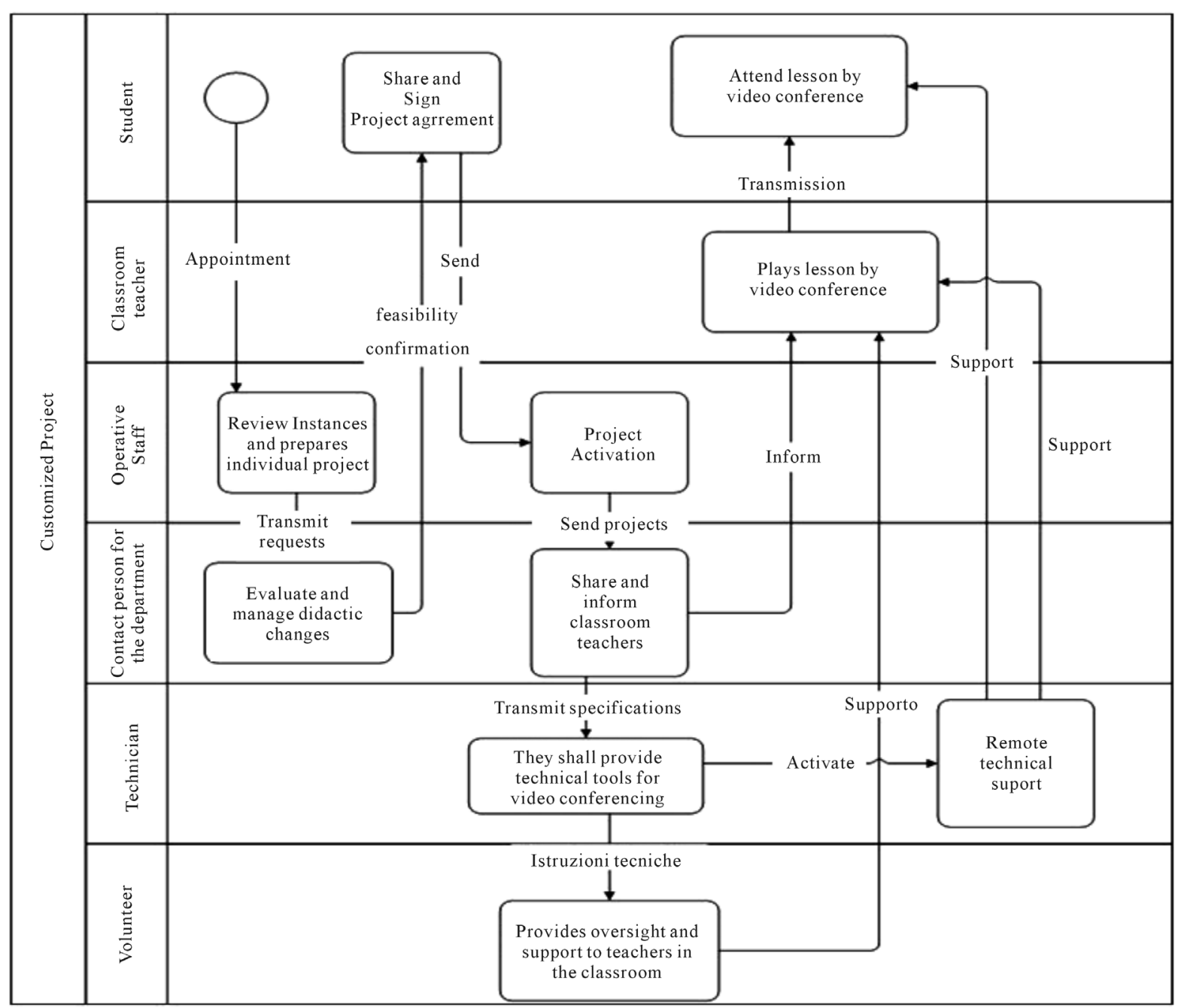

Figure 4. Operational workflow of the individual project of Case 3.

Then, has been considered a solution for the distance learning in real time by means of Representative of Department, with the Degree Board of the degree course based on bidirectional audio/video program without a conservative registration of sessions content (On explicit request of Didactic Commission).

In this particular case has been paid attention to the problems of the operative management in class that, for obvious reasons can't fall on teacher, and for which has recourse to Volunteers of Civil Service conveniently trained and that however for possible problems more difficult can do anyway advert to operators of technology; all that has been made possible by the wide availability of the modern connection band adsl and by efficiently of remote control instruments that facilitate enormously the distance technical support.

This planning solution has then allowed to the student to conserve all the possibilities of interaction with tutor and teacher make possible by presence in class but working from own domicile.

\section{Material Employ}

- $\quad$ n. 2 Pc notebook with Windows 7;

- Software for Videoconference (Skype);

- Software for remote assistance (Team Viewer).

\subsection{Case Study 4}

Mario is a student that because of a degenerative disease of neuro-muscular system saw decrease in course of 
the years progressively own capacities of motor control. The decrease in fact, besides, on capacities of ambulate and on control of the superior arts. Similarly at the previous case, then Mario has notable difficulties to move from own domicile and in addition difficulties in the use of keyboard and of mouse although has a great level of information education. Mario in fact has chosen a scientific course of study also in virtue of a particular provision for using technological instruments which the personal computer.

Therefore, being a computer technician, he has got a clear awareness of his necessities which fulcrum of the project is once again focused on the necessity of adapt the strict university patterns to the objective necessities of the boy to allow to him of commend his own potentialities.

Mario, in particular, has prefer to not follow courses in presence, therefore the sensitizes of teachers, both from the Operative staff personally, and by means of Representative of Department, is only focused to the provision of the didactic material in electronic way and to the availability of interact with the student through remote for explications and other things through common instruments which mail, chat and Skype. A specific work of analysis and configuration has then been conducted with the student in order to make him able to best exploit his remains capacities through the use of specifics interface hardware and software for facilitate and however reduce in minimal way the use of keyboard and of the mouse.

Then, to simplify and to accelerate, as far as possible, the use of keyboard, has been used a specific instrument named "shield" "Figure 5" that allow to guide the fingers on keyboard then is to simplify the use, certainly, it was necessary also chose a specific keyboard, compatible with the dimensions.

In "Figure 6" is presented the operational workflow of the individual project of Case 4.

To reduce at the minimal the use of keyboard, in cases of which require key significant amount of text, has been think to use a software for vocal control (Dragon Naturally speaking) (http://italy.nuance.com/index.htm), thanks to them, through the interpretation of the continuous speech, the student can easily transfer to computer lots of data, otherwise cannot be managed with the keyboard and the shield.

This software to be better employed, with a minimal number of errors di identification, require use of microphone of quality, a phase of initial training particularly looked after in which be on time intercepted and correct the (at first inevitable) errors of identification, a particular attention generally in first using, as in this phase, it contrive in large part of vocabulary and finally the provision of a certain number of macro commands specialized on the specific necessities of Mario.

Naturally all this has required that the operators of technology section do a specific activity of training and an assistance for the training phase of the software Dragon necessary in order to deliver to the student a dependable product and above all put him in condition of manage it as best he can.

With additional deepening with the student has come to light that he, because of him disability, complained too some problems of memorization of arguments of study, for that has been suggested the use of a program of word processing dedicate to the annotation and of another for creation of conceptual maps. The first to report

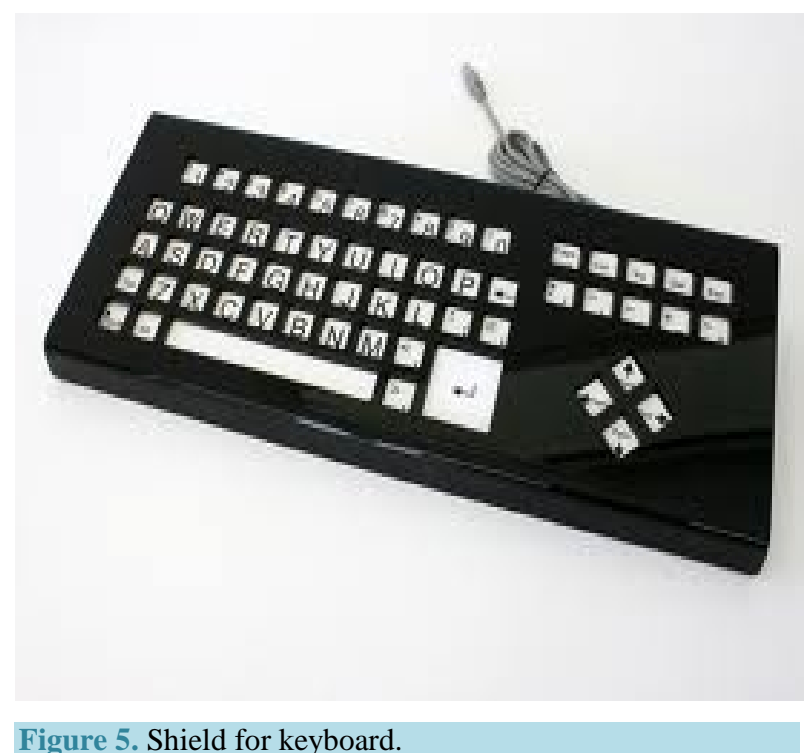

Figure 5. Shield for keyboard. 


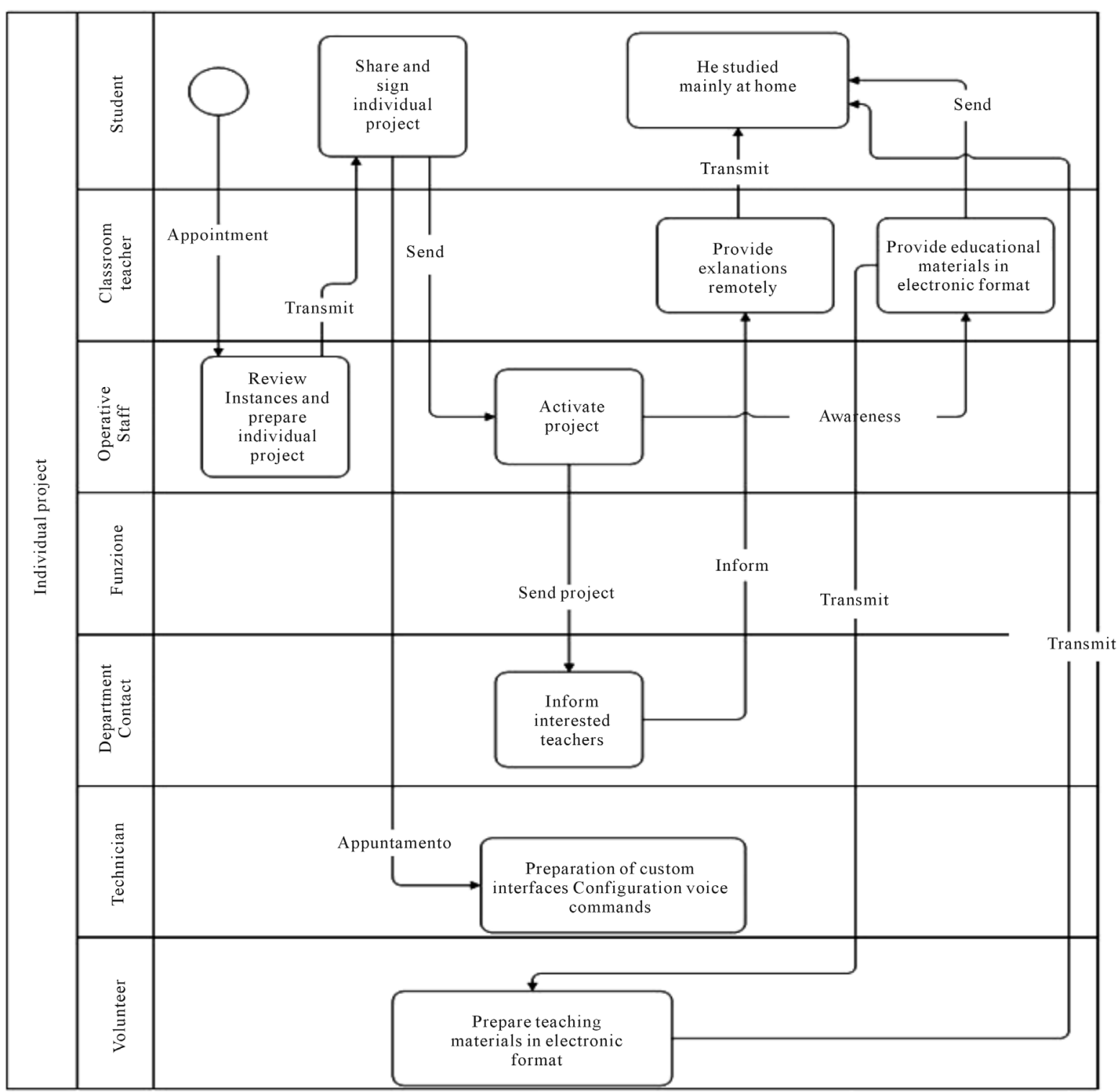

Figure 6. Operational workflow of the individual project of Case 4.

notes and synthetic annotations and the second to the figurative representation of concepts and of relations that unite them.

Finally, Mario has also been instructed on the use of the software of videoconference to do, if necessary, meet both the operators of the centre and the teachers that give their availability.

\section{Material Employ}

- Pc notebook with Windows 7;

- Software for the vocal identification of speech (Dragon Naturally Speaking);

- Software for the communication (Skype, mail client Thunderbird);

- Remote assistance software (TeamViewer);

- SwxMind, personal edition (http://www.speechcom.com).

\section{Conclusion}

The ITC technologies offer a wide range of solutions for various types of inclusion problems into scholastic and 
academic environment; it is however evident that, to approach inclusion problems only in technological sense, may be considered a big error. For example, preparing technical instruments or starting educational courses without taking into account the student's motivational aspects, may lead to a useless waste of resources that could be better utilized for other students and also for avoiding disillusion and frustration.

Then the multidisciplinary deign of every specific case is a necessary condition to whichever problem of inclusion.

Another important element is the quantity of operative hours inevitably necessary for the actualization of an inclusion project like, for instance, the digitalization of paper material, the student's coaching into the classroom, the technical support to the teacher etc.,. Such activities normally don't require an high specialization and skilled personnel but anyway, they require huge amount of man-hours of work, that in the most of academic and scholastic institution are not always available for supporting the inclusion project concerning each individual student.

In the case of the University "Federico II" these activities are provided by a team of Volunteers (Supported by a special scholarship “Civil Service” by the government).

The SiNAPSi university Centre every year enrol 40 volunteer and provide their training in order to make they able to support all the individual university inclusion project by the above indicated activities.

Another element key of success, but not less decisive, is represented by the teaching staff participation in order to make (with the volunteer support) their didactic material accessible in electronic format, but also for indicating alternative tests and examinations procedure.

On this point I am happy to outline, on the basis of the last 13 years of experience, that in the University "Federico II" an important change occurred in terms of awareness and responsibility about the thematic of inclusion, either in the teaching either in the administrative staff as well in the technical staff. However a correct planning of the intervention allow always a strong participation of the students in various phases that proceed from analysis to practical realization; and the motivation and willpower, at the same way of all other factors, can affect strongly on truly effective and on final performances achieved.

In the showed examples there are other technological elements, which systematically are used and which represented a common factor of success:

- The customization of the technological aids on the specific needs.

- The continuous training and the remote technical support during whole the intervention, represented step by step the best instrument for the growth of the student and for the monitoring of the process.

- The remote technical support also for teacher and for all the actors involved in the inclusion project.

The above experiences, then, confirm that the inclusion interventions through ICT technologies, reveal to be effective only if they are correctly managed, and if they are adequately arranged in a wider multidisciplinary inclusion project which all the professional participate to define.

\section{References}

Derer, K. (1996). A Survey of Assistive Technology Applications in Schools and Recommendations for Practice. Journal of Special Education Technology, 13, 62-80.

Dommett, E. J., Devonshire, I. M., Plateau, C. R., Westwell, M. S., \& Greenfield, S. A. (2011). From Scientific Theory to Classroom Practice. The Neuroscientist, 17, 382-388. http://dx.doi.org/10.1177/1073858409356111

Freda, C., Pepino, A., Pagliara, S. M., Ferraro, F., \& Zanfardino, F. (2008a). Mathematics and Dyslexia: Study of a Compensatory Software Solution. Congresso nazionale di bioingegneria 2008 ATTI, Pisa, 3-5 July 2008, Bologna: Patron Editore, 137-138.

Freda, C., Pepino, A., Pagliara, S. M., Ferraro, F., \& Zanfardino, F. (2008b). A Scientific Editor for Blind Users: Highlights and Results. Congresso nazionale di bioingegneria 2008 ATTI, Pisa, 3-5 July 2008, Bologna: Patron Editore, 219-220.

Ferreira, H., \& Diamantino, F. (2004). Enhancing the Accessibility of Mathematics for Blind People: The AudioMath Project. New York, NY: Springer Berlin Heidelberg.

Griffiths, T., \& Price, K. (2011). A Proposed Framework for Decision-Making for Assistive Communication Technology Support: Many Perspectives, but One Common Goal. Journal of Assistive Technologies, 5, 242-248. http://dx.doi.org/10.1108/17549451111190641

Karshmer, A. I., \& Chris, B. (2002). Access to Mathematics by Blind Students. In: K. Miesenberger, J. Klaus, \& W. Zagler (Eds.), Computers Helping People with Special Needs (pp. 471-476). New York, NY: Springer Berlin Heidelberg. http://dx.doi.org/10.1007/3-540-45491-8_90

OMS (2002). ICF, Classificazione Internazionale del Funzionamento, della Disabilità e della Salute, Erickson. 
Pepino, A., Freda, C., Ferraro, F., Pagliara, S., \& Zanfardino, F. (2006). BlindMath: A New Scientific Editor for Blind Students. In: Computers Helping People with Special Needs (pp. 1171-1174). Linz, July 206, Heidelberg: Springer, Vol. LCNS 4061.

Reeta, S. (2012). Blind Handicapped vs. Technology: How do Blind People Use Computers? International Journal of Scientific \& Engineering Research, 3.

The Kellogg College Centre for Research into Assistive Learning Technologies (2013). http://www.kellogg.ox.ac.uk/wp-content/uploads/2015/03/Current-Perspectives-on-Assistive-Learning-Technologies.pdf

Riemer-Reiss, M. L., \& Wacker, R. R. (2000). Factors Associated with Assistive Technology Discontinuance among Individuals with Disabilities. Journal of Rehabilitation, 66, 44-50.

Valerio P., Striano M., \& Oliverio S. (2013). (a cura di), Nessuno escluso. Formazione, inclusione sociale e cittadinanza attiva. Napoli: Liguori. 